\title{
A Review Paper on Contextual Information Retrieval
}

\author{
Charvi Sanjay Suri
}

${ }^{1}$ Shri Ramdeobaba College of Engineering and

Management, Computer Science, Nagpur, India

\section{ABSTRACT}

In a world where data is multiplying at a fierce rate, getting results of the queries from the whole stack of data is a tough job. In addition to that various words or phrases have multiple meanings and references. To get the result of such preference gets tougher with every step. Therefore, to get the desired results contextual information retrieval is used. There has been substantial growth in this subject and further studies are still going on. This paper gives an overview of some milestone researcher's studies which have made the search issues next to minimal.

KEY WORDS: CONTEXT, INFORMATION RETRIEVAL, CONTEXT PROCESSING, NATURAL LANGUAGE PROCESSING.

\section{INTRODUCTION}

There is an immense growth in the electronic data on the World Wide Web (WWW) and to make sure that the correct set of information is extracted, there is a need to make use of certain technics; one such technic is information retrieval. Even if the extracted information needed from the web is found, there is a chance it might be in a different context, not the one asked in our query. For Example, Taj can be a hotel in Mumbai, the seventh wonder of the world, the monument Taj Mahal in Agra, or the tea brand Taj we all love. To solve this issue we need to focus on contextual information retrieval. This technique will help to find an exact match of the query in a big stack of data on the internet.

Everybody around the world will be benefitted from growth in contextual information retrieval. The main use of it is to give exact results of the query asked for and refine the other results which are out of context.

\section{ARTICLE INFORMATION}

*Corresponding Author: surics@rknec.edu

Received 17th Oct 2020 Accepted after revision 25th Dec 2020

Print ISSN: 0974-6455 Online ISSN: 2321-4007 CODEN: BBRCBA

Thomson Reuters ISI Web of Science Clarivate Analytics USA and Crossref Indexed Journal

\section{Clarivate
Analytics}

NAAS Journal Score 2020 (4.31)

A Society of Science and Nature Publication,

Bhopal India 2020. All rights reserved.

Online Contents Available at: http//www.bbrc.in/

Doi: http://dx.doi.org/10.21786/bbrc/13.14/59
The basic goal of this paper is to present an overview of the experimental and theoretical works which directs the context in information retrieval.

Related Work: There has been much advancement in the field of contextual information retrieval over the years and some of them are mentioned in this review paper.

In (1987) Willam Collins developed the Cobuild English Language Dictionary, in which the established meanings of the term include:

1. The context of anything consists of the ideas, situations, events, or information that can relate to it and make it possible to understand.

2. If a statement is seen in context, it is considered with all the factors that are related to it rather than considered on everything it is supposed to mean so that it can easily be understood.

3. If a question, remark, statement, or anything else are taken or quoted out of context, it is only considered on its own, and the circumstances in which it was said are usually ignored. Therefore, it seems to mean something different from the intended meaning. [William Collins, 1987]

In (2000) based on the categories of context and the entities in which the context is evaluated the content information is classified by Dey \&t Abowd. 
Those 3 entities are given as follows:

1. Places (topographical space),

2. People (with their location, in groups or individual),

3. Things (Tangible objects or applications). [Dey. A.K, 2000]

In (2002) Context was explained in 5 categories by Goker Et Myrhaug as follows:

1. The environmental context, surrounding the user is in, like temperature, people, services, noise, and things.

2. The Spatial-temporal context that recognizes the spatial extent and time of the user.

3. The personal context tells us about the mental and physical information of the user.

4. The task context describes what the user working is on like his activities, tasks, and goals.

5. The social context tells us about the current social aspects of the user such as his friend's neighbors, allies, and co-workers. [Goker A, 2002]

In (2008) Mansourian pinpointed certain categories that were considered as main contextual elements that affect the search performance of users. Those 5 categories are as follows:

1. Web user's characteristics, it is divided into 3 subclasses,

(a) Thoughts,

(b) Feelings,

(c) Actions of the user while searching.

Even after completing the search, checking whether the search is done is giving valid or invalid results,

(2) The Type of the search engine,

(3) The Topic to be searched, whether it is related to the user's work or a daily life search.

(4) The situation in which the search is done which is also divided into 4 sub-classes

(a) Immediate search

(b) Type of search

(c) Place of search

(d) Importance of search.

(5) Features of the retrieved information resources, subdivided into 3 categories

(a) Ability to search

(b) Provision level

(c) Format of presentation. [Mansourian Y.,2008]

The context in information retrieval can be defined in many ways. There is no particular definition to cover the whole notion of context. In general terms, context can be defined as an important association of the user, interaction and object to the query or search words we put forth. [John D. Bransford, 2002] Discussion on the context in information retrieval is done in this paper. In the case of seeking and retrieving information, context can be referred to as whole data, applications, metadata and cognitive structures. All these data have an effect on the user's behavior and perception of relevance.
The interaction between user and system consists of a rich repository of possible or probable information on preferences, usage, experience, interests, and knowledge. [Ingwersen P, 2005] The context of the interaction is represented by information repository which is looked up for the source of evidence that allows user's information that needs to get captured precisely. It also helps to measure the relevance of supplied information with more specifications. Therefore, the estimation of relevance of the system can rely on both user's context- document accuracy as well as the results of query- document matching.

Figure 1: The multi-dimensional concept of context in IR [Tamine L.,2009]

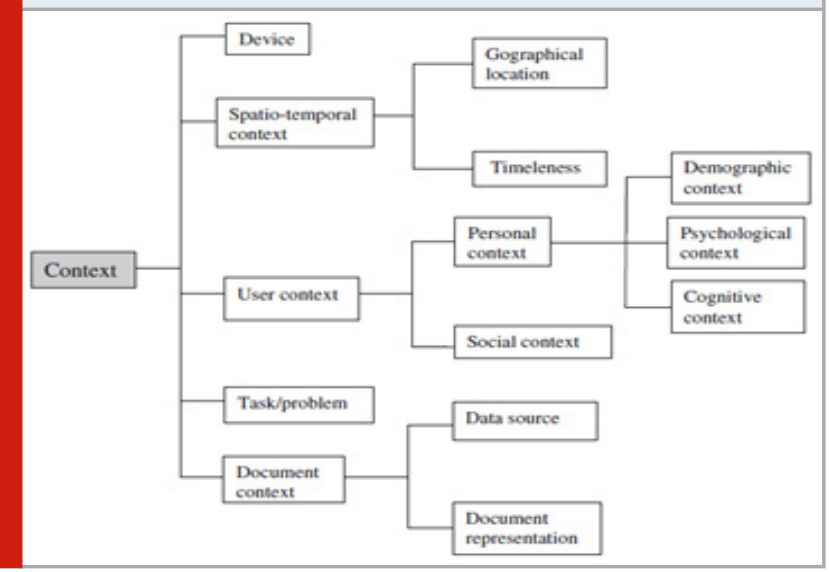

In (2009) Tamine, Boughanem and Daoud classified context into various categories as given in the figure (Fig.1) above. The context depends on:

(1) Device: A device helps us to access the user's information, like what kind of tool they are working on (e.g.) a computer, a mobile phone, a tablet, etc. Various devices have different characteristics and have their advantages and disadvantages. Using a mobile phone can get us fast results, but the queries might be ambiguous. On the other side, queries on a computer might process a little slow but will have a high level of interaction, and memory resources are huge. This makes the revival more sophisticated and gives apt outputs.

(2) Task/problem: The main goal of it is to decide what kind of search is to be made, facts are to be found or complete detail or an article is required here. There are various kinds of tasks in web search as transactional, exploration, navigational, or informational. It mainly acquires information about the location of the user. Just like maps in taxis helps the driver to get to the desired location.

(3) Spatial- temporal context: Given in the name itself, it consists of details about the geographical location and time. This provides us with information that addresses the user's situation in spatial-temporal applications. Just like in networks routing, and tourist guide applications, the data or query objects vary their location frequently. 
(4) User context: It contains all the personal and social details about the user.

(a) Personal Context:

1. Demographic Context: To customize the search, attributes such as language (English, Hindi, Hinglish, etc.) and gender (Male or female) are used.

2. Psychological Context: The mindset with which the user is searching the query also matters a lot. If the search is made quickly, it might be a result of anxiety and frustration, or if a person is calm and poised the searches are more accurate and fine. User's effective characteristics play an important role in influencing information-seeking behavior and its relevance assessments.

3. Cognitive Context: This is the most crucial dimension which leads most of the search queries. It checks whether the user's interest and user's levels of expertise are short-termed or long-termed.

4. (b) Social context: User's community is a great factor to look upon when we talk about social context. User's friends, colleagues, enemies as well as neighbors all come in this category. Recommendations are given while a search is based on these collaborative filtering techniques. These techniques are based on previously made searches, preferences, and similar users. The user community affects searches on a major scale.

5. Document context: There are two main subdimensions that could characterize the document context. The first one talks about the perception of the users on data source characteristic. The other talks about the document substitutes (relevant text fragments) such as form, colors, structural elements, citations, metadata. This tells us about how the document is designed (fonts, title, header, footer, paragraphs, words, style, layout) and the content of it.

\section{DISCUSSION AND RECOMMENDATION}

The contextual information retrieval is a vast topic to work on but it completely based on a few principles. All the studies show that context revolves around a person's life, choices, people around him, etc. According to Willam Collins, the context of anything consists of the ideas, situations, events, or information that can relate to it and make it possible to understand. Also if a question, remark, statement, or anything else are taken or quoted out of context, it is only considered on its own, and the circumstances in which it was said are usually ignored. On the other hand, Dev \& Abowd explains contexts as entities which are places, people, and things. Whereas Goker \&t Myrhaug has divided context into five categories which explains that environment and social structure have a very important role while deciding the context. Mansourian put forth a new aspect in front by telling the type of search engine can also affect the search. The ability of search, provision level, and format of presentation is equally important as feelings and social network of the user.
Tamine, Boughanem, and Daoud added to the studies that the device, as well as the data resource from which we extract the query, is of great importance too. All of the above researchers have put forth their valuable studies and cleared the concept of contextual information retrieval for future researchers interested to work in this area. The recommendation made is as follow, prediction of the searches from the current trends is going on the whole internet. For Example A meme is spread via the Internet, often through social media platforms and especially for humorous purposes. Many company brands use meme strategies for getting more market for their product. One of such example is the "Rasode me kon tha" meme. It brought back the show "Saath Nibhana Sathiya" back into the picture. When this meme was on-trend whenever a person wrote " $R$ " on google search, the first option that came to picture was the "Rasode me kon tha" meme. It was the most searched topic on the internet. There might be a possibility that a person who does not know about it will search about it. So we can cross-refer social media trends for getting a proper context.

\section{CONCLUSION}

The context has been a vital part of everybody's search and it provides an overview of its various definitions. It has been divided into different categories and discussed what factors are important to identify the context. In the end, a concept has been proposed that the trend going on social media needs to be considered while knowing the context. There has been a lot of work done in finding out what factors affect the context, now we should focus on solving the problems that come alongside when we do not get the results right.

\section{REFERENCES}

Collins. (1987). "Collins Cobuild English Language Dictionary". London: William Collins.

Dey, A. K. Et Abowd, G. D. (2000). "Towards a Better Understanding of Context and Context-Awareness", CHI 2000 Workshop on the What, Who, Where, When, and How of Context-Awareness.

Goker, A. \&t Myrhaug, H. I. (2002). "User context and personalization”, ECCBR Workshop on Case Based Reasoning and Personalization.

Ingwersen P, Jarvelin K (2005) The turn: integration of information seeking and information retrieval in context. Springer, Berlin

John D. Bransford, Ann L. Brown, and Rodney R. Cocking, How People Learn: Brain, Mind, Experience and School: Expanded Edition, 2000, Ch.3, Pg. 51-53 Kalyani Kamune, Avinash Agrawal, "Hybrid Approach to pronominal Anaphora Resolution in English Newspaper Text”, International Journal of Intelligent Systems and Applications.(IJISA), January 2015, ISSN. No. $2074-$ 904X (Print), ISSN: 2074-9058 (Online), PP.56-64 Mansourian, Y. (2008). "Contextualization of web searching: a grounded theory approach", The Electronic Library 26(2): 202-214.

Tamine L., Boughanem M., and Daoud M. (2009). "Evaluation of contextual information retrieval effectiveness: overview of issues and research". Knowledge and Information Systems, 24(1):1-34. 